\title{
Clinical research damaged by UK health service reforms
}

London. Clinical researchers in London's teaching hospitals say that the rapid pace of reforms to the National Health Service(NHS) are damaging the quality of their work. Uncertainties over funding are making them unwilling to initiate new projects, while changes in the patient referral patterns are posing obstacles to existing work. One professor at University College Hospital called the changes an "insidious erosion of clinical research".

The Department of Health (DoH), which is reviewing research funded by the NHS, says that the only evidence for their position is anecdotal. Yet many researchers say that the damage is hard to detect because the work straddles the border between clinical practice and basic research. In fact, DoH hopes that its review will make clear what type of research the NHS is funding, and who is doing it.

The reforms were introduced in April 1991 to improve the NHS's role as a provider of primary health care and to provide health authorities with greater financial independence. One result has been increased pressure to send patients to hospitals that offer the best value for money, which translates into a preference for treating patients in their home district.

This preference has hurt London's 14 teaching hospitals. The capacity of London hospitals far exceeds the health care needs of the local population, prompting repeated calls for reductions. In addition, the staff at these hospitals serve as teachers, clinical researchers and practitioners. At the same time, the division between their academic and clinical roles can be blurred. Staff employed by the NHS to perform routine care often become involved with research, and some academics contribute to clinical care.

All the teaching hospitals have suffered to some degree. The most recent sign of stress is the announcement by Bloomsbury and Islington Health Authority, facing a deficit of $£ 20$ million, that it will close 100 beds and eliminate 200 staff at University College and Middlesex Hospitals. Together, these two hospitals make up London's largest medical teaching complex.

Because the number of beds determines the number of students, and the funding tends to follow the students, fewer beds means less money flowing into the teaching hospitals. Most teaching of medical students involves a research component, and decreased funding also threatens to weaken research groups.

Researchers also fear that the cost-conscious health authorities will not enrol patients in clinical trials that involve expensive developmental drugs and will refuse to send them to hospitals where new techniques for diagnosis and therapy are being investigated. Those restrictions would erode their patient base, which constitutes a valuable resource. "These projects are often the research that solves immediate clinical problems, or that form the seed corn for longer term fundamental academic research," says David Delpy, a professor in medical physics at University College, London (UCL).

Cost considerations have already led health authorities to prohibit some doctors from referring patients to leukaemia trials. A report* from the Universities Funding Council (UFC) on the effects of the reforms expresses concern for the research taking place in specialist clinics for common disorders such as diabetes, hypertension and asthma. In the long term, there are fears that the NHS may devote most of its resources to common conditions and abandon work that does not have an immediate financial benefit.

The NHS has been undergoing a review of its research spending since it launched its first research strategy just over a year ago (see Nature 351, 7; 1991), with a pledge that research spending would be increased over the next four years. At present, around $£ 250$ million (US\$440 million) is spent a year,

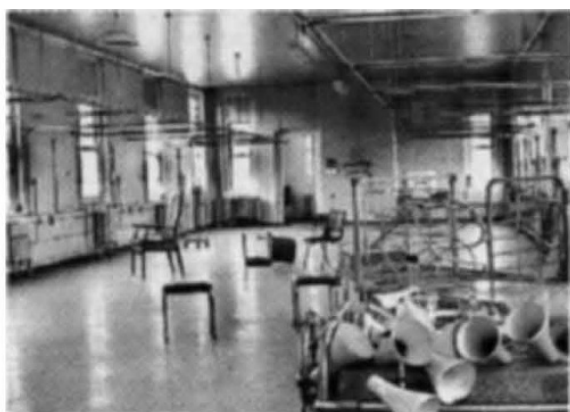

Closed wards reflect overcapacity problem.

representing about 1 per cent of the NHS budget. The aim is to reach 1.5 per cent by 1997-98.

However, until the review is complete and until the NHS completes its analysis of where it is currently spending money on research - there is considerable concern over which areas of research will be favoured. "There is a danger that there will be a reluctance to plan academic ventures when the future is so uncertain," says David Linch, professor of haematology at UCL. The first results of the review were visible last week, when the central research and development committee of the NHS sent out an announcement soliciting proposals for research projects in certain areas of mental health.

Ian Mundell

* Second Report on the Effects of the NHS Reforms on Medical and Dental Education and Research (Universities Funding Council, Northavon House, Coldharbour Lane, Bristol BS16 1QD, UK.)

\section{Russian academy vote excludes Jews}

Moscow. There is consternation in the Russian Academy of Sciences (RAS), and outside as well, after this month's election of new members: almost all candidates with Jewish surnames were blackballed. Many academicians themselves are dismayed by this demonstration of antisemitism among the scientific elite.

The outcome was unexpected. Usually, the general meeting of the RAS formally approves choices made earlier by its 18 academic divisions, subject only marginally to the settling of old scores. But this month, nearly all the candidates proposed by the departments of economics, international economics, philosophy and law and nuclear physics were rejected.

The list of rejections from nuclear physics includes such prominent figures as Semyon Gerstein, Isay Gurevich and Ilya Feinberg, all with Jewish names. But Alexander Mikhailov was also rejected, apparently because of the misfortune of having recently become a government minister.

In the event, the elections were extraordinary. Some successful candidates would not have been elected conventionally, including members of the new Nomenclatura such as Vladimir Shorin (chairman of the Parliamentary Commission on Science and Technology), who becomes an academician, and Ruslan Khasbulatov, the Speaker of the Russian Parliament (corresponding member). Also elected academician was Igor Shafarevich, an eminent mathematician who is also a well-known ideologist of antisemitism.

Indignation at the results, and the conviction that they had been unfairly overlooked, then prompted the corresponding members of the RAS to demand that they should automatically be promoted to full membership. The leadership promised instead that there would be a further round of elections.

After the elections, the president of the academy voiced his surprise at the outcome, but Academician L. I. Abalkin may have been the only one to speak openly of antisemitism. Abalkin criticized the election system for allowing an expert in the humanities or a microbiologist to vote on the candidacy of a physicist or a jurist. But the results of this month's election suggests that the trouble does not lie with the electoral system alone. Vladimir Pokrovsky 